\title{
REVIEW
}

\section{Silver or silver nanoparticles: a hazardous threat to the environment and human health?}

\author{
Nagender Reddy Panyala ${ }^{1}$, Eladia María Peña-Méndez ${ }^{2}$, Josef Havel ${ }^{1,3}$ \\ ${ }^{1}$ Department of Chemistry, Faculty of Science, Masaryk University, Brno, Czech Republic \\ ${ }^{2}$ Department of Analytical Chemistry, Nutrition and Food Chemistry, Faculty of Chemistry, University of La \\ Laguna, Tenerife, Spain \\ ${ }^{3}$ Department of Physical Electronics, Faculty of Science, Masaryk University, Brno, Czech Republic
}

Received $12^{\text {th }}$ April 2008.

Revised $27^{\text {th }}$ May 2008.

Published on line $23^{\text {rd }}$ June 2008.

\begin{abstract}
Summary
Nanotechnology is a rapidly growing science of producing and utilizing nano-sized particles that measure in nanometers. These nanomaterials are already having an impact on health care. Now-a-days we are using nanoproducts in various fields. Of these, silver nanoparticles are playing a major role in the field of nanotechnology and nanomedicine.

Their unique size-dependent properties make these materials superior and indispensable as they show unusual physical, chemical and biological properties. Silver nanoparticles have potential antimicrobial activity towards many pathogenic microbes. Along with this antimicrobial activity, silver nanoparticles are showing unacceptable toxic effects on human health and the environment. The chronic exposure to silver causes adverse effects such as permanent bluish-grey discoloration of the skin (argyria) and eyes (argyrosis). Besides argyria and argyrosis, exposure to soluble silver compounds may produce other toxic effects like liver and kidney damage, irritation of the eyes, skin, respiratory and intestinal tract and changes to blood cells. This review summarizes the hazardous effects of silver nanoparticles in the environment and theirs toxic effects on human health.
\end{abstract}

Key words: silver nanoparticles - antimicrobial activity - argyria - argyrosis - silver toxicity

\section{INTRODUCTION}

Only in the last few years has nano-technology begun to evolve into a valuable science. And only in the last

\footnotetext{
$\bowtie$ Josef Havel, Department of Chemistry, Faculty of Science, Masaryk University, Kotlářská 2, 61137 Brno, Czech Republic

昌 Havel@chemi.muni.cz

留 $+420-549494114$

且 $+420-549492494$
}

few years has the technology existed to produce this cutting edge silver suspension. Only now has silver arrived as the natural immune system assistant it was in the early days of mankind when it was plentiful in its metallic form in ground water. For the optimum function of body immunity, everyone needs nano-silver circulating in their bloodstream (http://www.nano-silver.com/).

Silver is a naturally occuring precious metal, most often as a mineral ore in association with other elements. It has been positioned as the 47 th element in the periodic table, having a atomic weight of 107.8 
and two natural isotopes $106.90 \mathrm{Ag}$ and $108.90 \mathrm{Ag}$ with abundance 52 and $48 \%$. It has been used in a wide variety of applications as it has some special properties like high electrical and thermal conductivity (Nordberg and Gerhardsson 1988). Ancient civilizations used this precious metal in medicine, eating utensils, plates, cups, food containers, jewellery, money/coins, clothes, building materials, and as a disinfectant for water and human infection.

Silver metal and silver dressings, when used in reasonable amounts, has no negative effects on the human body and it has a natural antimicrobial activity (Margaret et al. 2006, Sarkar et al. 2007) towards many pathogens such as bacteria (Hill and Pillsbury 1939, Morones et al. 2005, Zhang and Sun 2007), viruses, fungi, yeast etc. Silver salts have been used for the treatment of mental illness, nicotine addiction, gastroenteritis and infectious diseases like syphilis and gonnorrhea (Marshall and Schneider 1977, Shelley et al. 1987, Gulbranson et al. 2000, Drake et al. 2005). New silver coated catheters are used because they stop the infections that were common place with the old ones (Samuel et al. 2004). To protect us from food poisoning, silver particles are now being put in cutting boards, table tops, surface disinfectants, and refrigerators. Silver is woven and impregnated into fabrics to kill bacteria that cause body odor.

But ecologists have warned that widespread use of such a powerful antimicrobial could have serious negative consequences for bacteria in natural systems if nano-anti microbials are released in waste streams etc. There is also growing evidence that as well as being toxic to bacteria, silver nanoparticles are also highly toxic to mammalian cells (Braydich-Stolle et al. 2005, Wen et al. 2007, Gopinath et al. 2008). Silver nanoparticles have been shown to damage brain cells (Hussain et al. 2006), liver cells (Hussain et al. 2005) and stem cells (Braydich-Stolle et al. 2005). Even with prolonged exposure to colloidal silver or silver salt deposits of metallic silver under the skin cause skin diseases like argyria or argyrosis (Chen et al. 2007).

Even in its bulk form, silver is extremely toxic to fish (Hogstrand et al. 1996), algae, some plants, fungi (Eisler et al. 1996), crustaceans and bacteria like nitrogen fixing heterotrophic and soil forming chemolithotrophic bacteria (Albright et al. 1974).

The toxicity of a metal is influenced by several factors like solubility, binding specificity to a biological site, etc. The toxic effect or heavy metal poisoning is defined as, "Any functional or morphologic change in the body produced by an ingested, injected, inhaled or absorbed drug, chemical, or biological agent". In contrast,
Westhofen et al. (1986) observed that the affinity of silver for membrane and neuronal structures and the deposition of silver as an insoluble compound $\left(\mathrm{Ag}_{2} \mathrm{~S}\right)$ induce the progression of clinical diseases like generalized argyria. Argyrosis is a pathologic bluish-black pigmentation in a tissue resulting from the deposition of an insoluble albuminate of silver (http://medical-dictionary.thefreedictionary.com/ar gyrosis).

In the environment or in living organisms the silver can be present in different forms. The most common is metallic silver, silver salts (ionic silver), silver complexes and colloidal silver. Metallic silver dissolves in acids and salts like e.g. silver nitrate is formed. Aqueous solution of soluble silver nitrate contains silver in the form of hydrated silver cations $\mathrm{Ag}\left(\mathrm{H}_{2} \mathrm{O}\right)_{n}{ }^{+}$which is typical "ionic silver". However, silver cation can be complexed with various organic ligands and even if silver cation is still present in the molecule, the overall charge of the complex can be neutral. Furthermore, highly stable complexes are known which are not dissociated at all in the solution or biological liquids. Colloidal silver is a colloidal state of silver-containing particles in water with $1 \mathrm{~nm}$ to 1 micron silver or silver-containing particles. The term "colloidal" was coined by English chemist Thomas Graham (in 1800) who was later on called as "father of colloid chemistry". Colloidal silver can be in the form of super-fine metallic form or in the form of insoluble silver compounds, finally dispersed in solution which shows small or high turbidity. Nano silver means usually nano-sized particles of nanometre size and the term is connected to colloidal silver or identical. There are now many commercial products, some are named as "NanoSilver". The term nano-silver refers to the nanoparticulate size of the silver particles of 5-50 nm. Nanosilver has a more active surface area and better porosity than commercial silver (Alt et al. 2004).

The aim of this paper is to give an overview and analyze the various toxic effects of silver or nanosilver on human health and the environment.

\section{WHAT IS NANOSILVER?}

NanoSilver is a commercial name for pure de-ionized water with superfine silver in suspension (http://www.nano-silver.com). Nanoparticles size is from 5 to $50 \mathrm{~nm}$. Most of the silver is in the form of metallic silver nano-particles. The remaining silver is in ionic form. Because of the small size of the particles, the total surface area of the silver exposed in solution is maximized, resulting in the highest 
possible effect per unit of silver (Alt et al. 2004). As a result, a very small concentration of silver in NanoSilver provides greater effectiveness inside the body than silver solutions in the colloidal form of many times greater concentration.

Nano-silver products are characterized by high percentage of silver metallic form. This is important because ionic silver becomes silver chloride in the stomach or bloodstream. Solubility of silver chloride is low. In addition, the silver chloride is less effective than metallic silver. Only metallic particles survive the hydrochloric acid of the stomach to remain effective inside the body (http://www.nano-silver.com).

\section{SILVER CLUSTERS AND SILVER NANOPARTICLES}

Silver atoms can form under various conditions so called clusters which can eventually further aggregate forming silver nanoparticles. Silver clusters can be formed e.g. by the action of laser during ablation of metallic silver or silver salts. For example, charged silver clusters like $\mathrm{Ag}_{2}{ }^{+}, \mathrm{Ag}_{3}{ }^{+}$are formed by laser desorption/ionisation of $\mathrm{Ag}(\mathrm{s})$ or $\mathrm{Ag}$ salts and $\mathrm{Ag}_{\mathrm{n}}$ clusters with $n$ up to $50-60$ were described (Staudt et al. 2000). Due to the two isotopes of silver, in mass spectra characteristic isotopic envelopes are developed.

An example of experimental and theoretical mass spectrum for $\mathrm{Ag}_{2}$ cluster is given in Fig. 1. Evidently, there are three combinations of the silver isotopes yielding three peaks in mass spectrum. Silver cluster $\mathrm{Ag}_{8}$ can be stabilized in erionite channels. Erionite is a kind of zeolite which shows cavities with diameter $0.63 \mathrm{~nm}$ and length $1.5 \mathrm{~nm}$, such elongated cavities are connected by small windows with a diameter 0.25 $\mathrm{nm}$. The interconnections between the neighbouring channels are with twisted 8-member rings (with sizes $0.36 \times 0.52 \mathrm{~nm})($ Ogden et al. 1999). Mass spectrum and the structure of this interesting $\mathrm{Ag}_{8}$ cluster are shown in Fig.2. Silver isotopes give rather rich isotopic pattern.

\section{CHARACTERISTICS OF SILVER NANOPARTICLES, THEIR UPTAKE, INTERACTIONS AND THEIR CYTOTOXICITY IN VARIOUS ORGANS AND CELL MEMBRANES}

There are many processes to synthesize silver nanoparticles e.g. electrochemical reduction, and/or irradiation, etc. (Sergeev et al. 1999, Sun and Xia 2002, Zhang et al. 2002, Pyatenko et al. 2004, Bogle et al. 2006, Chen and Schluesener 2007). The literature (Elechiguerra et al. 2005, Jose et al. 2005, Lok et al. 2006) demonstrated that silver nanoparticles with certain size ranges and shapes have special interactions with bacteria and viruses. Through all these basic physiochemical properties, silver can easily be absorbed in cellular environments and it makes adhesive interactions with biological macromolecules and can be translocated within the human body.

Silver can enter the human body through various portals like ingestion, inhalation of dusts or fumes containing silver (Phalen and Morrow 1973, Furchner et al. 1968), skin contact, contact with jewellery and by the application of burn creams etc. Existing literature (Drake and Hazelwood 2005) demonstrated that silver also gains entry into the body through the use of acupuncture needles (Sato et al. 1999), catheters (Saint et al. 2000), dental amalgams (Catsakis and Sulica 1978), or through accidental puncture wounds (Rongioletti et al. 1992).

Silver ions may enter through various semi-open poruses which are present in the human body, i.e., lungs, gastrointestinal tract, respiratory tract, mucous membranes of the urinogenital tract and skin mostly in the form of silver protein complexes (Chen et al. 2007). These silver nanoparticles can bind to different proteins and causes phagocytosis.

Although silver is absorbed in and metabolized in soft tissues, available experimental animal studies and human clinical reports have shown that it enters into tissues of the central nervous system or it causes neurotoxic damage. According to Cheng et al. (2004), Zhang and Sun (2007b), silver ions can also enter in to the human body through the female genital tract. As per existing literature (Armitage et al. 1996), inhaled silver deposited in the lung can be absorbed through the wall of the alveolus. Some of the inhaled particles are eliminated by mucocilliary action in the lungs.

Nearly $10-20 \%$ of the ingested silver metal is absorbed in the gastrointestinal tract, mainly by the duodenum and small intestine. Absorption of ingested metal in the skin has also been reported, but it may depend on damage to the epithelium layer being present (Boosalis et al. 1987).

Silver and silver salts are distributed around the body and they accumulated mainly in the liver, kidney and spleen. Chronic exposure of silver leads to irreversible deposition in subcutaneous and mucous membranes. Through this deposition, melanin production is enhanced, stimulated by the presence of silver, leading to discoloration of the skin (Armitage et al. 1996, Greene and Su 1987). 


\section{TOXIC EFFECTS OF NANOSILVER OR SILVER ON HEALTH}

Silver has potentially toxic effects on human health and it can enter into the human body through various portals. Previous literature (Kone et al. 1988) indicated that $\mathrm{Ag}^{+}$causes early changes in the permeability of the cell membrane to $\mathrm{K}^{+}$and then to $\mathrm{Na}^{+}$at concentrations that do not limit $\mathrm{Na}^{+}, \mathrm{K}^{+}-\mathrm{ATP}$ activity or mitochondrial function.
As per the existing literature (Seung-heon et al. 2006), it has been demonstrated that silver nanoparticles show intensive toxic effects on the proliferation and cytokine expression by peripheral blood mononuclear cells (PMBCs). At levels of over $15 \mathrm{ppm}$, nano-silver was found to have a significant cytotoxic effect on PBMCs, and Phytohaemagglutinin-induced cytokine production was significantly inhibited by nano-silver (Shin et al. 2007).

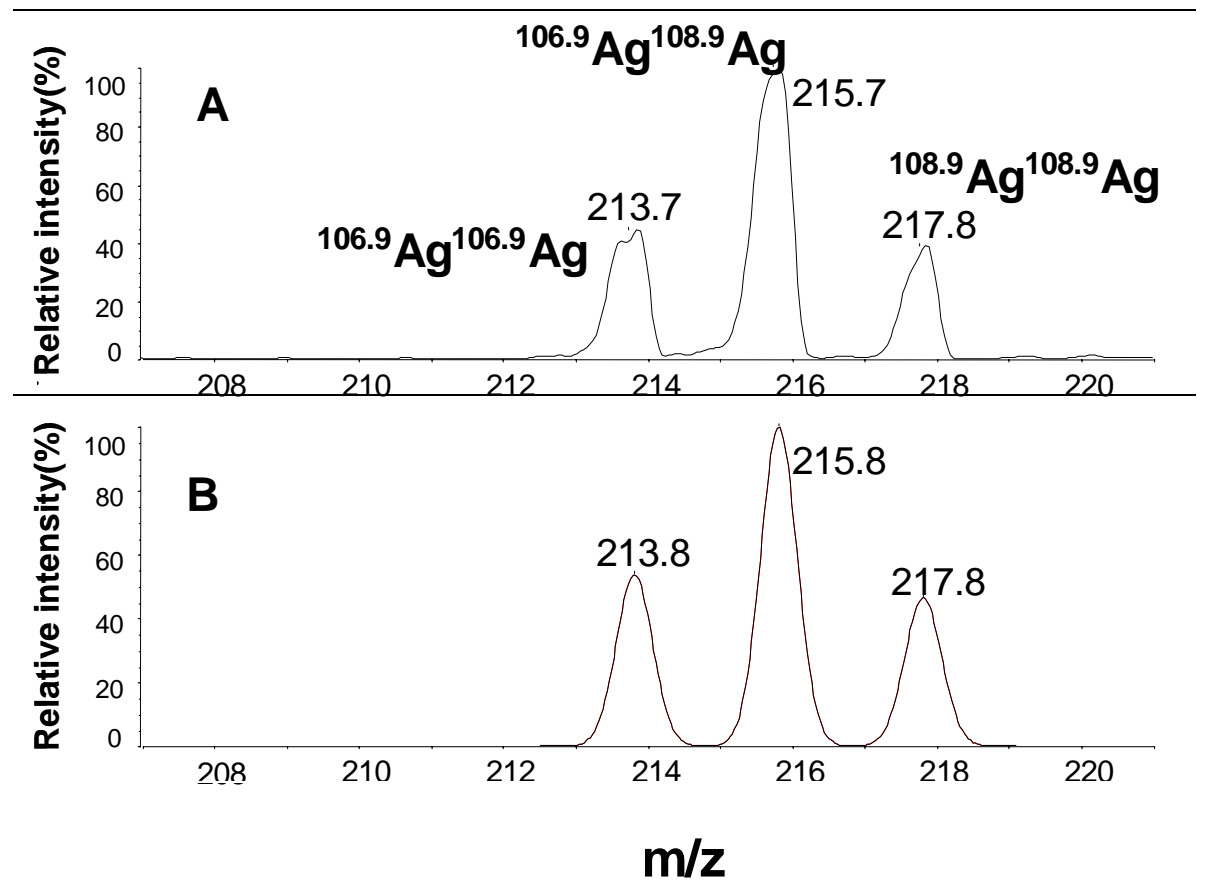

Fig. 1. Experimental (A) and theoretical (B) mass spectra of $\mathbf{A g}_{2}{ }_{2}$ cluster cation. Commercial MALDI-TOF MS instrument (Axima-CFR, Schimadzu biotech, Japan) with a pulsed nitrogen laser of a wavelength of $337 \mathrm{~nm}$ was used for laser desorption ionization of silver nitrate with addition of trifluoroacetic acid.

Conditions: the linear-positive mode.

Silver does not only cause dermal and cosmetic toxic effects, but also it causes death in animals. Soto et al. (2005) have recently shown that silver nanoparticles can be nearly $50 \%$ more toxic than chrysolite asbestos. Nanoparticles, such as silver nanoparticles, are showing severe toxic effects on the male reproductive system. The identified research suggests that nanoparticles cross the blood-testes barrier and are deposited in the testes, and that there is potential for adverse effects on sperm cells (McAuliffe et al. 2007).
In the literature of Burd et al. (2007), it was demonstrated that commercially available silver-based dressings (Acticoat ${ }^{\mathrm{TM}}$, Aquacel $^{\circledR} \mathrm{Ag}$, Contreet $^{\circledR}$ Foam, PolyMem ${ }^{\circledR}$ Silver, Urgotul ${ }^{\circledR}$ SSD) are also showing potential cytotoxic effects. They assessed their cytotoxicity in various cultures such as in a monolayer cell culture, a tissue explants culture model and a mouse expurgated wound model. The results showed that Acticoat ${ }^{\mathrm{TM}}$, Aquacel ${ }^{\circledR} \mathrm{Ag}$, and Contreet $^{\circledR}$ Foam, when pre-treated with specific solutes, were likely to produce the most significant 
cytotoxic effects on both cultured keratinocytes and fibroblasts, while PolyMem ${ }^{\mathbb{B}}$ Silver and Urgotul ${ }^{\mathbb{R}}$ SSD demonstrated the least cytotoxicity. The cytotoxicity correlated with the silver released from the dressings as measured by the silver concentration in the culture medium.

\section{EFFECTS ON TISSUES AND ORGANS}

By over-exposure, silver can be accumulated in the liver, skin, kidneys, corneas, gingival, mucous membranes, nails and spleen etc. (Rosenman et al.
1979, Sue et al. 2001). Silver ions show a high affinity for thiol in the liver (Baldi et al. 1988, Drake et al. 2005). Silver can accumulate and shows some toxic effects in organs and tissues. Venugopal and Luckey (1978) noted that argyria can be considered a mechanism to detoxify silver by sequestering it in the tissues as harmless silver-protein complexes or silver sulphide.

Nanoparticles, such as silver nanoparticles, can bind to different tissues and can cause potential toxic effects like cell activation, producing reactive oxygen species, which are more toxic to tissue, inflammation and finally all these processes gradually lead to cell death (Xia et al. 2006).

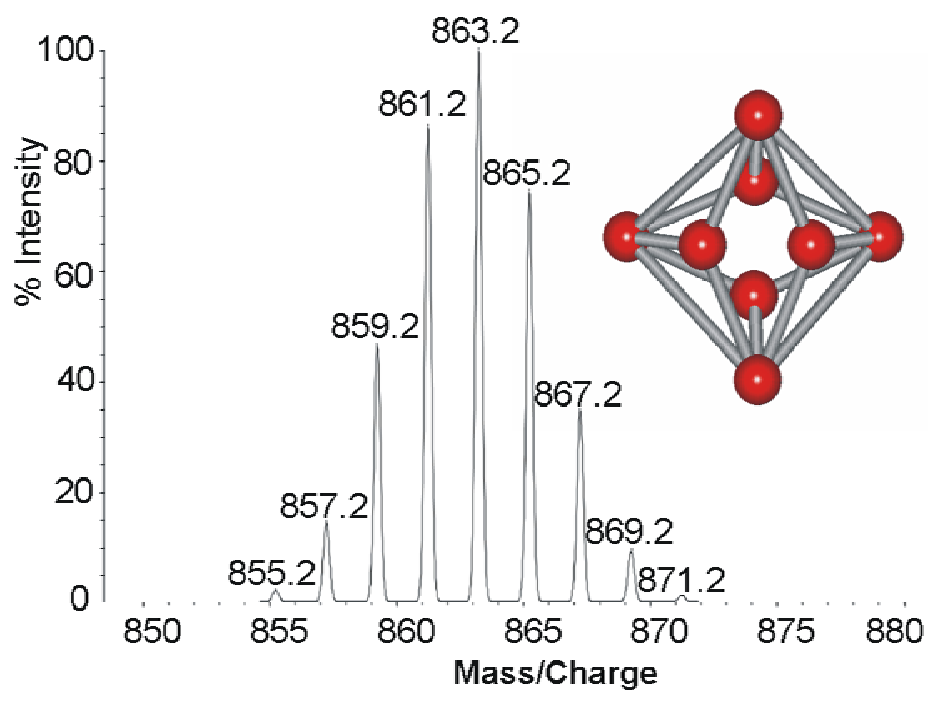

Fig. 2. An example of $\mathbf{A g}_{8}$ cluster structure and theoretical mass spectrum demonstrating rich isotopic envelope.

As a result of the experimental studies by Gopinath and Gogoi et al. (2008), it is known that nanomaterials can pass through cell membranes easily and cause severe toxic effects on human health. They have concluded that silver nanoparticles in higher concentrations $\left(>44.0 \mu \mathrm{g} \mathrm{ml}^{-1}\right)$ are necrotic to cells, leading to rapid cell membrane rupture. Recent studies have shown that nanoparticles can easily pass through the blood-brain and blood-testes barriers (Borm and Kreyling 2004) in mouse models.

Through the experimental studies of Takenaka et al. (2001), it has been learned that elemental silver nanoparticles can enter through the cardiovascular system. In their experiments, they have studied pulmonary and systemic distribution of inhaled ultra fine elemental silver nanoparticles in rats. They have observed that Ag was found in the lungs immediately after the end of exposure. They have found significant amounts of Ag in the blood, liver, kidney, spleen, brain and heart. Importantly they have detected high Ag concentrations in nasal cavities, especially in the posterior portion and lung-associated lymph nodes. By these experiments, it is now known that after phagocytosis of inhaled silver nanoparticles 
by alveolar macrophages, there are Ag nanoparticles in the region of lungs, mostly on the alveolar walls.

\section{Effects on central nervous system (CNS)}

The localization of exogenous silver is distributed heterogeneously in the central nervous system. It can enter through the blood-brain barrier and accumulate in large motoneurones in the brain stem and spinal cord, neurons in cerebellar nuclei and glia. By the usage of $\mathrm{Ag}$ in animal experiments, it is now known that the biological half-life of silver in CNS is longer than in other organs (Scott and Hamilton 1950, Furchner et al. 1968, Phalen and Morrow 1973, Rungby and Danscher 1983a, b). By prolonged administration of different silver compounds like silver lactate, silver nitrate and some silver proteins like Protargol, silver accumulates in neurons and glia. Prolonged exposure to silver shows toxic effects on CNS such as cerebral ataxia (Aaseth et al. 1981).

\section{Respiratory effects}

The respiratory system is a major portal for nanoparticles. Actually larger sized particles than nanoparticles will be seized by the microcilliary system which is present in the respiratory tract. But ultra fine particles like nanoparticles can be deposited on the alveolar space. It has been proved that inhaled silver nanoparticles do not interfere with the microcilliary elimination process (Lippmann et al. 1980). At the alveolar region these particles can be submersed into the surfactant lining of alveoli. By this submersion, nanoparticles can produce surface radicals and reactive oxygen species, which are more toxic to alveolar surfaces (Chen et al. 2007). Some recent studies indicated that exposure to nanoparticles can induce oxidative stress in lung epithelial cells (Kaewamatawong et al. 2006, Limbach et al. 2007, Sharma et al. 2007) and also in alveolar macrophage cells (Soto et al. 2008). These toxic effects are due to their intensive catalytic activity (Limbach et al. 2007). So it can be said that having such a large surface area and oxidative property, only silver nanoparticles can produce highly reactive species like reactive oxygen species at the intra-alveolar spaces (Chen et al. 2007). Through these interactions with alveolar surfaces, silver nanoparticles can cause irritation in the respiratory tract (Rosenman et al. 1987). By inhalation of silver dust or fumes, alveoli and bronchial tissue will be stained. But this staining is not harmful to human health (Brooks 1981, Drake et al. 2005).

\section{Argyria and argyrosis}

It is known and acknowledged that long-term use of colloidal silver or silver salts, like $\mathrm{AgNO}_{3}$, deposit metallic silver under the skin and abdominal viscera, turning people's skin an ashen-grey colour, an affliction known as argyria (irreversible pigmentation of skin) and/or argyrosis (pigmentation of eyes) (Marshall and Schneider 1977, Lee et al.1994, Prescott et al. 1994, Fung et al.1996, Gulbranson et al. 2000, Menaguale et al. 2003, Brandt and Park et al. 2005, Padlewska et al. 2007). As per the literature of Drake et al. (2005), argyria and argyrosis are caused by the placement of silver-containing materials into the skin or body (Espinal et al. 1996), inhalation of silver particles (Rosenman et al. 1979), or by usage of silver-containing medicines (Fung and Bowen 1996, Gulbranson et al. 2000, Tomi et al. 2004), dental materials (Watanabe 1989) etc.

Dietl et al. (1984) showed that manic depressive psychosis will develop at about the same time if not a short time after cutaneous argyria has been diagnosed. It leads to a ruptured aortic aneurysm and finally death. In this case they observed some deposits of silver in the skin, mucous membranes, heart, kidney, liver, in the central nervous system and in the leptomeninges and choroid plexus also.

Even the usage of silver and silver creams can cause cutaneous side effects including hypersensitivity reactions, allergic contact dermatitis, erythema multiforme and systemic argyria in humans (Fisher et al. 2003).

Generally argyria and argyrosis may be classified into two major types, i.e., localized and generalized (Greene and Su 1987). Localized argyria is caused by the direct contact of silver and silver-containing substances. Small silver particles can enter the body through sweat glands or through needle punctures (Buckley et al. 1965). In this case the most commonly affected areas are mucous membranes, eyes and hands (Breitstadt 1995). In this generalized argyria, silver granules are found most commonly around the eccrine glands, in the walls of blood vessels, and along elastic fibres (Robinson-Bostom et al. 2002).

Generalized argyria symptoms include pigmentation on the skin, eyes, face, ' $V$ of the neck', waist, bald scalp, hands, nails and forearms (Legat et al. 1998, Bouts 1999, Johnston et al. 1999, Graham et al. 2004, Brandt et al. 2005, Bianchi et al. 2006, ). Their light microscopical studies have revealed that fine granules cluster in the periadnexal basement membrane and dermal elastic fibres (White et al. 2003).

In generalized argyria, the degree of slate-grey cutaneous discoloration varied from barely perceptible to pronounce. Silver-containing granules deposit in and around cutaneous adnexal structures. Histochemical studies suggested that the granules consisted of silver sulphide. Indiscriminate use of currently available silver-containing medications can result in generalized argyria (Pariser 1978). 


\section{TOXIC EFFECTS OF SILVER OR NANO-SILVER ON THE ENVIRONMENT}

Silver, along with its potential antimicrobial activity, also causes adverse effects not only in the human body (Fung and Bowen 1996) but also it causes some toxic effects in aquatic systems and soil microbial communities.

\section{Effects on soil communities}

Silver has some potential toxic effects on beneficial bacteria in soil, which play a major role in nitrogen fixation. For instance, according to the report of Senjen (2007), it has been discovered that there is currently very little research available regarding the effects of silver nanoparticles on soil microbial communities. Silver, with its potential bactericidal activity, inhibits soil microbial growth at levels below the concentrations of other heavy metals (Murata et al. 2005, Throback et al. 2007). It shows toxic effects on human-friendly microbes like heterotrophic (nitrogen-fixing and ammonifying bacteria) and chemolithotrophic bacteria in soil communities. Chemolithotrophic bacteria belong to the lithotrophic family of microbes and consume inorganic material. These organisms deliver many crucial nutrients which are most essential in soil formation (http://en.wikipedia.org/wiki/Lithotroph). These soil bacteria can play a key role in nitrogen fixing and the breakdown of organic matter. These bacteria also form symbiotic relationships with legumes plants, which provide a major source of fixed nitrogen for both these and other plants. By showing potential toxic effects on denitrifying bacteria, silver disrupts denitrification processes leading to eco-system disruption. Denitrification is a bacterium driven process in which nitrates are converted to nitrogen gas in some soils, wetlands and in some other wet environments. Environmental denitrification is important because excess nitrates can reduce plant productivity, which in turn can result in eutrophication in rivers, lakes and marine ecosystems, and are a drinking water pollutant (Senjen 2007).

\section{Effects on aquatic systems}

Silver has some unexpected adverse toxic effects on aquatic systems like lakes, rivers etc. For instance, in freshwater fish, the acute toxicity of Ag appears to be caused solely by ionic $\mathrm{Ag}^{+}$interacting at the gills, inhibiting basolateral $\mathrm{Na}^{+}, \mathrm{K}^{+}$-ATPase activity. Disruption of this enzyme inhibits active $\mathrm{Na}^{+}$and $\mathrm{Cl}^{-}$ uptake and therefore osmoregulation by the fish (Wood 1999). Recent toxicity studies with macro-invertebrates in the San Francisco Bay have indicated that silver may still be adversely affecting the health of the estuarine system (Flegal et al. 2007). Silver causes lethal damage to hepatocytes in rats and finally it leads to cell death (Baldi et al. 2002).

\section{Case studies}

Various forms of silver and silver-containing compounds cause adverse effects in humans and animals. Most studies discuss the various toxic effects of silver on the human body and the environment following intensive ingestion and inhalation of silver compounds. A number of studies describe the effects of occupational exposure to metallic and soluble silver compounds.

As discussed earlier, silver has a potential antimicrobial activity towards many pathogens (Hill and Pillsbury 1939) and it has been used in the past for medication purposes. According to the medical literature citation, numerous cases of argyria were observed after colloidal silver ingestion. In a typical case study by Chang et al. (2006), data from a 59year-old man who was suffering from skin colour change was analyzed. It was revealed that he had ingested colloidal silver two to three times a year for at least the previous two years, whenever he felt a 'cold' coming on. The patient believed that the colloid silver had antibiotic properties. Along with this skin colour change, some other symptoms were also visible like hyperlipidemia, hypertension, diabetes, gastroesophageal reflux disease, benign prostatic hypertrophy, and post-traumatic stress disorder. After a critical examination, it was reported that he had a diffuse blue-grey appearance on his face, mostly on his cheeks and nose with slight sparing of the periorbital and paranasal areas. Finally, it was concluded that the ingestion of colloidal silver appears to be an increasing practice among patients using 'alternative health' practices and can lead to specific pathological and clinical findings like argyria.

In the literature of Drake et al. (2005), it was mentioned that colloidal silver protein had been used as an allergy and cold medication (Bouts 1999, Gulbranson et al. 2000, Tomi et al. 2004), in eye drops to alleviate soreness (Loeffler and Lee 1987) and for the treatment of various ailments (White et al. 2003). Prolonged usage of this silver protein as a medication caused discoloration in the fingernails, ocular agyrosis and generalized argyria.

Silver nanoparticles can show a potential cytotoxic effect on mammalian germ line stem cells. In the experimental case study of Braydich-Stolle et al. (2005), the cytotoxicity effects of silver nanoparticles on mammalian germ line stem cells were investigated. In this study, the effect on cell morphology, mitochondrial function, membrane leakage etc. was taken into consideration. It was 
concluded that silver nanoparticles at $10 \mu \mathrm{g} / \mathrm{ml}$ and above concentration showed dramatic changes like necrosis and apoptosis of cells. Silver nanoparticles at $5-10 \mu \mathrm{g} / \mathrm{ml}$, drastically reduced mitochondrial function and cell viability.

In the second case study by White et al. (2003), data from a 58-year-old man suffering from worsening facial discoloration over 3 years. He drank colloidal silver protein solution for at least one year but was unable to estimate his total consumption. He believed that this silver protein had properties to treat and prevent various diseases like dandruff and colonic cancer. On a critical examination, a deep-blue/grey discoloration of the skin, face, neck, bald scalp, hands and forearms was observed. His fingernails showed a blue discoloration extending from the lanulae to halfway along the nail plate.

Using a light microscope, they observed fine granules clustered in the periadnexal basement membranes and dermal elastic fibres. Electron microscopic studies also revealed bright granules below the dermal/epidermal junction. After all these studies, it was concluded that the precise mechanism of silver deposition in argyria is not fully understood, but ingestion of silver is thought to cause deposition of silver-protein complexes. Elemental silver is reduced to silver sulphide in the skin. This process is catalysed by sunlight in a process similar to that harnessed in photography. The process, combined with melanocyte stimulation, causes the cutaneous discolouration (White et al. 2003).

In the third case study (Tomi et al. 2004) data was analyzed from a 42-year-old non-smoking white man complaining of skin discoloration. He had initially noticed a slight blue-grey tinge to his skin some months previously, but which had increased over time. On clinical examination, they have found a peculiar slate, blue-grey discolouring of the entire tegument, sclera, mucosal surfaces and nails. He had applied one to two $10 \mathrm{ml}$ bottles of a topical vasoconstrictor, Coldargan (Sigmapharm, Vienna) weekly to ameliorate the symptoms of allergic rhinitis. In microscopic studies they also observed brownish-black perivascular pigment deposits in muscle, nerve, sweat glands and dermis. So finally it was concluded that the person was suffering from generalized argyria on the basis of above mentioned clinical symptoms.

Along with this case study, we witnessed our own case of argyria in an elderly Indian woman who, for several years, had applied the silver sulfadiazine cream every day to heal her wound and contact dermatitis. After using the silver sulfadiazine cream, a scar-localized argyria developed within a post surgical wound and area of severe contact dermatitis. So it can be concluded that by applying this silver sulfadiazine cream to wounds and dermatitis, it causes some cutaneous side effects including hypersensitivity reactions, allergic contact dermatitis, erythema multiforme and sytemic argyria.

In the fourth case study, Rosenman et al. (1987), a cross sectional study on workers engaged in manufacturing precious metal powders was carried out. Around 27 workers, $96 \%$ of the workers, had raised urine silver concentrations (range 0.5-52.0 $\mu \mathrm{g} / 1$, mean $11.3 \mu \mathrm{g} / \mathrm{l}$ ) and $92 \%$ of workers had raised blood silver concentrations (range 0.05-6.2 $\mu \mathrm{g} / 100$ $\mathrm{ml}$, mean $1.0 \mu \mathrm{g} / 100 \mathrm{ml})$. Most workers had symptoms of respiratory irritation and nose bleeds were reported in eight $(30 \%)$ of the 27 workers. Deposition of silver in the cornea of the eye in around five of eight $(63 \%)$ workers was observed. Raised urinary enzyme N-acetyl-B-D glucosaminidase (NAG) was detected in four individuals and was correlated with blood silver concentrations and age. It was noted that kidney function appeared to have been adversely affected by exposure at work but it has not been confirmed as, up to this study, it was not known if exposure to silver causes any decrement or not in the kidney function.

In our own cross sectional case study, we have analysed twenty six workers from an industrial plant in Hyderabad, India which eliminates silver and silver compounds like silver nitrate and silver oxide from industrial wastes. By the consumption of drinking water mixed with these silver containing industrial wastes, we have concluded that some people were suffering from cutaneous diseases like argyria and argyrosis.

This cross sectional study revealed that five people had generalized argyria and fifteen had argyrosis. Ten of the twenty six workers had complained of gastrointestinal irritation and some allergic and hypersensitivity reactions. This symptom was significantly associated with silver in the blood and deposition of silver in the periadnexal basement membrane and dermal elastic fibres (White et al. 2003). However, the permanent discoloration and potential effect of some allergic reactions suggest the need to limit exposure to silver.

\section{DISCUSSIONS AND CONCLUSIONS}

After reviewing the literature one fact is noticeable. Over the past decades, the usage of silver containing medications has become more prevailing because of their potential antimicrobial and bactericidal activity and people are choosing silver containing medicines as an alternative health supplement. Earlier, we 
mentioned that silver has a natural antimicrobial activity (Margaret et al. 2006, Sarkar et al. 2007) towards many pathogens such as bacteria (Hill and Pillsbury 1939, Morones et al. 2005, Zhang and Sun 2007), viruses, fungi, yeast etc.

Some people believe that silver has properties such that it can protect them from diseases like colonic cancer and some skin diseases like dermatitis. The explanation of the protection effect is still not understood. It is suggested that silver can disrupt the bacterial cell wall. At minimal and reasonable concentrations of silver, there are no side effects on human health. Even though it is has potential antimicrobial activity, prolonged exposure to silver causes intensive diseases like argyria and argyrosis.

According to Drake et al. (2005), the uptake of silver into the human body is often much higher when it is administered orally as a medication than from occupational exposure like inhalation of silver compounds. The majority of occupational exposure reports involve soluble silver compounds, which seem to cause toxic effects at lower concentrations than metallic and insoluble silver compounds. For example, blood-silver concentrations found by Williams and Gardner (1995) and Armitage et al. (1996), were considerably higher than that found in workers exposed to metallic silver or insoluble silver compounds.

But in many of the studies we cannot say that silver could definitely be associated with an adverse health outcome. For example the study of Rosenman et al.(1987) was an attempt to investigate the effects of silver on kidney function. It was found that creatinine clearance was depressed and urinary enzyme NAG levels were significantly raised in the exposed group. However, it was difficult to determine if silver caused any adverse effects on kidney function or not because the workers had also been exposed to many other nephrotoxic agents.

Several cross sectional studies were carried out and it was reported that argyria is the most frequent adverse outcome from exposure to silver. For example even in a typical recent case study done by Chang et al. (2006), it was reported that the prolonged ingestion of silver containing medicines causes colour changes to the skin and a blue-grey appearance on the face. Along with these symptoms some other symptoms like hypertension, diabetes, gastroesophageal reflux disease, benign prostatic hypertrophy and post-traumatic stress disorders were also observed. But in some cases, many of the workers complained of decreased vision at night. Many ophthalmologic studies have been conducted and they have concluded that decreased vision at night is associated with the deposition of silver in the cornea.
According to the literature, it was reported that many people are using silver and silver compounds as medications for symptoms such as allergies and colds (Bouts 1999, Gulbranson et al. 2000, Tomi et al. 2004) and eye diseases (Loeffler and Lee 1987).

In conclusion, it has been reported that silver nanoparticles can bind to proteins and enzymes in mammalian cells. These silver nanoparticles can make adhesive interactions with cellular membranes and produce highly reactive and toxic radicals like reactive oxygen species, which will cause inflammation and destroy cells like mitochondria. Subsequently they produce apoptogenic factors that cause cell death and necrosis in the cellular environment. Silver nanoparticles can show intensive toxic effects on the mitochondrial function and cell viability and they can produce lytic enzymes which can cause apoptosis and necrosis. It has been reported that ingestion of colloidal silver (a suspension of silver in microparticles and/or nanoparticles) has also been linked with neurological problems, kidney damage, stomach upset, headache, fatigue and skin irritation (Senjen 2007). Silver affects denitrification bacteria such strongly that, in reality, disrupts the bacterium driven environmental denitrification processes. As a consequence it results a great up to catastrophic eutrophication in rivers, lakes and marine ecosystems (Senjen 2007).

Having a tremendous surface area and small particle size, nanoparticles can make potential interactions with membrane surfaces and can easily translocate and become distributed throughout the human body. Taking into account their physicochemical and biological properties, it is likely that nanoparticles possess unique toxicity mechanisms. It remains to be determined whether silver nanoparticles and other nanoparticles will introduce new mechanisms of injury from which new pathologies may result. Finally for silver, whether nano-sized or not, there are always the problems of argyria and argyrosis in humans and eutrophication in the environment.

\section{ACKNOWLEDGEMENTS}

Supports from theAcademy of Sciences of the Czech Republic, project KAN 101630651 (Nanotechnology for the Society) and of the Grant Agency of the Czech Republic, project No. 525/06/0663 are greatly acknowledged. E.M.P-M. and J.H. acknowledge the partial support from University of La Laguna, La Laguna, Spain. 


\section{REFERENCES}

Aaseth J, Olsen A, Halse J, Hovig T: Argyria-tissue deposition of silver as selenide. Scand. J. Clin. Lab. Invest. 41:247-251, 1981.

Albright LJ, Wilson EM: Sub-lethal effects of several metallic salt-organic compounds combinations upon heterotrophic microflora of a natural water. Water Res. 8:101-105, 1974.

Alt V, Bechert T, Steinrucke P, Wagener M, Seidel P, Dingeldein E, Domann E, Schnettler R: An in vitro assessment of the antibacterial properties and cytotoxicity of nanoparticulate silver bone cement. Biomaterials 25:4383-4391, 2004.

Armitage SA, White MA, Wilson HK: The determination of silver in whole blood and its application to biological monitoring of occupationally exposed groups. Ann. Occup. Hyg. 40:331-338, 1996.

Baldi C, Minoia C, Di Nucci A, Capodaglio E, Manzo L: Effects of silver in isolated rat hepatocytes. Toxicol. Lett. 41:261-269, 1988.

Bianchi L, Orlandi A, Di Stefani A, Ricci R, Chimenti S: "Familial" generalized argyria. Arch. Dermatol. 142:789-90, 2006.

Bogle KA, Dhole SD, Bhoraskar VN: Silver nanoparticles:synthesis and size control by electron irradiation. Nanotechnology 17:3204-3208, 2006.

Boosalis MG, McCall JT, Ahrenhalz DH, Solem LH, McClain CJ: Serum and urinary silver levels in thermal injury patients. Surgery 101:40-43, 1987.

Borm PJ and Kreyling WJ: Toxicological hazards of inhaled nanoparticles-potential implications for drug delivery. J. Nanosci. Nanotechnol. 4:521-551, 2004.

Bouts BA: Images in clinical medicine. Argyria. N. Engl. J. Med. 340:1554, 1999.

Brandt D, Park B, Hoang M, Jacobe HT: Argyria: secondary to ingestion of homemade silver solution. J. Am. Acad. Dermatol. 53:S105-S107, 2005.

Braydich-Stolle L, Hussain S, Schlager JJ, Hofmann MC: In vitro cytotoxicity of nanoparticles in mammalian germline stem cells. Toxicol. Sci. 88:412-419, 2005.

Breitstadt R: Occupational exposure limits for metallic silver. In Proc. $2^{\text {nd }}$ European Precious Metals Conference, Lisbon, Portugal 1995, pp. $1-13$.

Brooks SM: Lung disorders resulting from the inhalation of metals. Clin. Chest Med. 2:235-254, 1981.

Buckley WR, Oster CF, Fasset DW: Localized argyria II. Chemical nature of the silver containing particles. Arch. Dematol. 92:697-705,
1965.

Burd A, Kwok CH, Hung SC, Chan HS, Gu H, Lam WK, Huang L: A comparative study of the cytotoxicity of silver-based dressings in monolayer cell, tissue explant, and animal models. Wound Repair Regen. 15:94-104, 2007.

Catsakis LH, Sulica VI: Allergy to silver amalgams. Oral Surg. Oral Med. Oral Pathol. 46:371-5, 1978.

Chang ALS, Khosravi V, Egbert B: A case of argyria after colloidal silver ingestion. J. Cutan. Pathol. 33:809-811, 2006.

Chen X, Schluesener HJ: Nanosilver:A nanoproduct in medical application. Toxicol. Lett. 176:1-12, 2007.

Cheng D, Yang J, Zhao Y: Antibacterial materials of silver nanoparticles application in medical appliances and appliances for daily use. Chin. Med. Equip. J. 4:26-32, 2004.

Dietl HW, Anzil AP, Mehraein P: Brain involvement in generalized argyria. Clin. Neuropathol. 3:32-38, 1984.

Drake PL, Hazelwood KJ: Exposure-related health effects of silver and silver compounds: A Review. Ann. Occup. Hyg. 49:575-585, 2005.

Eisler R.: A review of silver hazards to plants and animals. In Andren AW, Bober TW. (eds.): Proc. 4th Int. Conf. Transport, Fate and Effects of Silver in the Environment, Madison, Wisconsin 1996, pp. 143-144.

Elechiguerra JL, Burt JL, Morones JR, Camacho-Bragado A, Gao X, Lara HH, Yacaman MJ: Interaction of silver nanoparticles with HIV-1. J. Nanobiotechnology 3: art. No. 6, 2005.

Espinal ML, Ferrando L, Jimenex DF: Asymptomatic blue nevus-like macule. Diagnosis: localized argyria. Arch. Dermatol. 132:461-464, 1996.

Fisher NM, Marsh E, Lazova R: Scar-localized argyria secondary to silver sulfadiazine cream. J. Am. Acad. Dermatol. 49:730-732, 2003.

Flegal AR, Davis JA, Connor MS, Conaway $\mathrm{CH}$ : Sources, transport, fate, and toxicity of pollutants in the San Francisco Bay estuary. J. Environ. Res. 105:0-4, 2007.

Fung MC, Bowen DL: Silver products for medical indications: risk-benefit assessment. J. Toxicol. Clin. Toxicol. 34:119-126, 1996.

Furchner JE, Richmond CR, Drake GA: Comparative metabolism of radionuclides in mammals-IV. Retention of silver- $110 \mathrm{~m}$ in the mouse, rat, monkey and dog. Health Phys. 15:505-14, 1968.

Gopinath P, Gogoi SK, Chattopadhyay A, Gosh SS: Implications of silver nanoparticle induced cell apoptosis for invitro gene therapy. J. Nanobiotechnoogy 19: art. No. 075104, 2008.

Graham SA, O'Meara JM: The feasibility of 
measuring silver concentrations in vivo with $\mathrm{x}$ ray fluorescence. Phys. Med. Biol. 49:N259-266, 2004.

Greene RM, Su WPD: Argyria. Am. Fam. Physician 36:151-154, 1987.

Gulbranson SH, Hud JA, Hansen RC: Argyria following the use of dietary supplements containing colloidal silver protein. Cutis 66:373-376, 2000.

Hill WR, Pillsbury DM: Argyria: The Pharmacology of Silver. MD:Williams \& Wilkins Company, Baltimore 1939.

Hogstrand C, Wood CM. The toxicity of silver to marine fish. In Andren AW, Bober TW (eds.): Proc. $4^{\text {th }}$ Int. Conf. Transport, Fate and Effects of Silver in the Environment, Madison, Wisconsin 1996, pp. 109-112.

Hussain SM, Hess KL, Gearhart JM, Geiss KT, Schlager JJ: In vitro toxicity of nanoparticles in BRL 3A rat liver cells. Toxicol. in Vitro 19:975-983, 2005.

Hussain SM, Javorina MK, Schrand AM, Duhart HM, Ali SF, Schlager JJ: The interaction of manganese nanoparticles with PC-12 cells induces dopamine depletion. Toxicol. Sci. 92:456-463, 2006.

Johnston AM, Memon AA: A Medical Mystery. N. Engl. J. Med. 340:1011, 1999.

Jose RM., Jose LE, Alejandra C, Katherine H, Juan BK, Jose TR, Miguel JY: The bactericidal effect of silver nanoparticles. Nanotechnology 16:2346-2353, 2005.

Kaewamatawong T, Shimada, A, Okajima A, Inoue $\mathrm{H}$, Morita $\mathrm{T}$, Inoue $\mathrm{K}$, Takano H.: Acute and subacute pulmonary toxicity of low dose of ultrafine colloidal silica particles in mice after intratracheal instillation. Toxicol. Pathol. 34:958-965, 2006.

Kone BC, Kaleta M, Gullans SR: Silver ion $\left(\mathrm{Ag}^{+}\right)$-induced increases in cell membrane $\mathrm{K}^{+}$and $\mathrm{Na}^{+}$permeability in the renal proximal tubule: Reversal by thiol reagents. J. Membr. Biol. 102:11-19, 1988.

Lee SM, Lee SH: Generalized argyria after habitual use of $\mathrm{AgNO}_{3}$. J. Dermatol. 21:50-53, 1994.

Legat FJ, Goessler W, Schlagenhaufen C, Soyer HP: Argyria after short-contact acupuncture. Lancet 352:241, 1998.

Limbach LK, Wick P, Manser P, Grass RN, Bruinink A, Stark WJ: Exposure of engineered nanoparticles to human lung epithelial cells: Influence of chemical composition and catalytic activity on oxidative stress. Environ. Sci. Technol. 41:4158-4163, 2007.

Lippmann M, Yeates DB, Albert RE: Deposition, retention, and clearance of inhaled particles. Br.
J. Ind. Med. 37:337-362, 1980.

Loeffler KU, Lee WR: Argyrosis of the lacrimal sac. Graefe's Arch. Clin. Exp. Ophthalmol. 225: 146-150, 1987.

Lok CN, Ho CM, Chen R, He QY, Yu WY, Sun H, Tam PK, Chiu JF, Che CM: Proteomic analysis of the mode of antibacterial action of silver nanoparticles. J. Proteome Res. 5:916-924, 2006.

Margaret IP, Lui SL, Poon VKM, Lung I, Burd A: Antimicrobial activities of silver dressings: an in vitro comparison. J. Med. Microbiol. 55:59-63, 2006.

Marshall JP II, Schneider RP: Systemic argyria secondary to topical silver nitrate. Arch. Dermatol. 113:1077-1079, 1977.

McAuliffe ME, Perry MJ: Are nanoparticles potential male reproductive toxicants? A literature review. Nanotoxicology 1:204-210, 2007.

Menaguale G, Fazio R, Fazio M: Argyria: A case following the prolonged use of a rhinologic drug. Esper. Dermatol. (Roma) 4:299-303, 2003.

Morones JR, Elechiguerra JL, Camacho A, Holt K, Kouri JB, Ramirez JT, Yacaman MJ: The bactericidal effect of silver nanoparticles. J. Nanotechnology 16:2346-2353, 2005.

MurataT, Kanao-koshikawa M, Takamatsu T: Effects of $\mathrm{Pb}, \mathrm{Cu}, \mathrm{Sb}, \mathrm{In}$ and $\mathrm{Ag}$ contamination on the proliferation of soil bacterial colonies, soil dehydrogenase activity, and phospholipid fatty acid profiles of soil microbial communities. Water, Air Soil Pollut. 164:103-118, 2005.

Nordberg G, Gerhardsson LS: Silver. In Seiler HG, Sigel H, Sigel A (eds.): Handbook on Toxicity of Inorganic Compounds. Marcell Dekker, New York 1988, pp. 619-624.

Ogden JS, Bogdanchikova NE, Corker JM, and Petranovskii VP: Structure of silver clusters embedded in erionite channels. Eur. Phys. J. D 9:605-608, 1999.

Padlewska K, Schwartz R: Argyria. In Khan S, Vinson, RP, Miller JJ, Gelfand, James, WD, Gross PR (eds): eMedicine: Dermatology and Online Medical Reference 2007. eMedicine.com, $\mathrm{I} \mathrm{n} \mathrm{c} ., \quad \mathrm{O} \mathrm{m} \mathrm{ha,} \quad \mathrm{NE} \quad 20007$. (http://www.emedicine.com/)

Pariser RJ: Generalized argyria. Clinicopathologic features and histochemical studies. Arch. Dermatol. 114:373-380, 1978.

Phalen RF, Morrow PE: Experimental inhalation of metallic silver. Health Phys. 24:509-518, 1973.

Prescott RJ, Wells S: Systemic argyria. J. Clin. Pathol. 47:556-557, 1994.

Pyatenko A, Shimokawa K, Yamaguchi M: Synthesis of silver nanoparticles by laser ablation in pure water. J. Appl. Phys. A: Mater. Sci. Proces. A79:803-806, 2004. 
Robinson-Bostom L, Pomerantz D, Wilkel C, Mader R, Lerner L, Dufresne R, Flotte T: Localized argyria with pseudo-ochronosis. J. Am. Acad. Dermatol. 46:222-229, 2002.

Rongioletti F, Robert E, Buffa P, Bertagno R, Rebora A: Blue nevi-like dotted occupational argyria. J. Am. Acad. Dermatol. 27:1015-1016, 1992.

Rosenman KD, Seixas N, Jacobs I: Potential nephrotoxic effects of exposure to silver. Br. J. Ind. Med. 44:267-272, 1987.

Rosenman KD, Moss A, Kon S: Argyria: clinical implications of exposure to silver nitrate and silver oxide. J. Occup. Med. 21:430-435, 1979.

Rungby J, Danscher G: Localization of exogenous silver in brain and spinal cord of silver exposed rats. Acta Neuropathol. 60:91-98, 1983a.

Rungby J, Danscher G: Neuronal accumulation of silver in brains of progeny from argyric rats. Acta Neuropathol. 61:258-262, 1983b.

Saint S, Veenstra DL, Sullivan SD, Chenoweth C, Fendrick AM: The potential clinical and economic benefits of silver alloy urinary catheters in preventing urinary tract infection. Arch. Intern. Med. 160:2670-2675, 2000.

Samuel U, Guggenbichler JP: Prevention of catheter-related infections: the potential of a new nano-silver impregnated catheter. Int. J. Antimicrob. Agents 23S1:S75-S78, 2004.

Sarkar S, Jana AD, Samanta SK, Mostafa G: Facile synthesis of silver nano particles with highly efficient anti-microbial property. Polyhedron 26:4419-4426, 2007.

Sato S, Sueki H, Nishijima A: Two unusual cases of argyria: the application of an improved tissue processing method for X-ray microanalysis of selenium and sulphur in silver-laden granules. $\mathrm{Br}$. J. Dermatol. 140:158-163, 1999.

Scott KG, Hamilton JG: The metabolism of silver in the rat with radiosilver used as an indicator. Publ. Pharmacol. 2:241-262, 1950.

Senjen R: Nano silver - a threat to soil, water and human health? Friends of the Earth Australia March 2007 . Available at: http://nano.foe.org.au/node/189.

Sergeev MB, Kasaikin AV, Litmanovich AE: Cryochemical synthesis and properties of silver nanoparticle dispersions stabilised by poly(2-dimethylaminoethyl methacrylate). Mendeleev Commun. 9:130-132, 1999.

Seung-heon S, Mi-kyung Y, Jeung-kyu K: The effects of nano-silver on the proliferation and cytokine production in peripheral blood mononuclear cells. Jpn. J. Rhinol. 45:269, 2006.

Sharma CS, Sarkar S, Periyakaruppan A, Barr J, Wise K, Thomas R, Wilson BL, Ramesh GT: Single-walled carbon nanotubes induces oxidative stress in rat lung epithelial cells. J. Nanosci. Nanotechnol. 7: 2466-2472, 2007.

Shelley WB, Shelley ED, Burmeister V: Argyria: the intradermal "photograph", a manifestation of passive photosensitivity. J. Am. Acad. Dermatol. 16: 211-217, 1987.

Shin SH, Ye MK, Kim HS, Kang HS: The effects of nano-silver on the proliferation and cytokine expression by peripheral blood mononuclear cells. Int. Immunopharmacol. 7:1813-1821, 2007.

Soto KF, Carrasco A, Powell TG, Garza KM, Murr LE: Comparative in vitro cytotoxicity assessment of some manufactured nanoparticulate materials characterized by transmission electron microscopy. J. Nanoparticle Res. 7:145-169, 2005.

Soto KF, Murr LE, Garza KM: Cytotoxic Responses and Potential Respiratory Health Effects of Carbon and Carbonaceous Nanoparticulates in the Paso del Norte Airshed Environment. Int. J. Environ. Res. Public Health 5:12-25, 2008.

Staudt C, Heinrich R, Wucher A: Formation of large clusters during sputtering of silver. Nucl. Istrum. Methods Phys. Res. B: 164-165, 677-686, 2000.

Sue YM, Lee JY, Wang MC, Lin TK, Sung JM, Huang JJ: Generalized argyria in two chronic hemodialysis patients. Am. J. Kidney Dis. 37:1048-1051, 2001.

Sun Y, Xia Y: Shape controlled synthesis of gold and silver nanoparticles. Science 298:2176-2179, 2002.

Takenaka S, Karg E, Roth C, Schulz H, Ziesenis A, Heinzmann U, Schramel P, Heyder J: Pulmonary and systemic distribution of inhaled ultra fine silver particles in rats. Environ. Health Perspect. 4 :547-551, 2001.

Throback IN, Johansson M, Rosenquist M, Pell M, Hansson $\mathrm{M}$, Hallin S: Silver $\left(\mathrm{Ag}^{+}\right)$reduces denitrification and induces enrichment of novel nirK genotypes in soil. FEMS Microbiol. Lett. 270:189-194, 2007.

Tomi NS, Kranke B, Aberer W: A silver man. Lancet 363: 532, 2004.

Venugopal B, Luckey TD (eds.): Metal toxicity in mammals. In Chemical Toxicology of Metals and Metalloids. Academic Press, New York 1978, pp. 32-36.

Watanabe K: Histopathological study of damage to periodontal tissues by silver alloy metals in rats. J. Jpn. Assoc. Periodontal. Res. 31:1021-1046, 1989.

Wen HC, Lin YN, Jian SR, Tseng SC, Weng MX, Liu YP, Lee PT, Chen PY, Hsu RQ, Wu WF, Chou CP: Observation of growth of human fibroblasts on silver nanoparticles. J. Phys. Conf. Ser. 61:445-449, 2007. 
Westhofen M, Schafer H: Generalized argyrosis in man: neurotological, ultrastructural and X-ray microanalytical findings. Arch. Otorhinolaryngol. 243:260-264, 1986.

White JML, Powell AM, Brady K, Russell-Jones R: Severe generalized argyria secondary to ingestion of colloidal silver protein. Clin. Exp. Dermatol. 28:254-256, 2003.

Williams N, Gardner I: Absence of symptoms in silver refiners with raised blood silver levels. Occup. Med. 45:205-208, 1995.

Wood CM, Playle RC, Hogstrand C: Physiology and modelling of mechanisms of silver uptake and toxicity in fish. Environ. Toxicol. Chem. 18:71-83, 1999.
Xia T, Kovochich M, Brant J, Hotze M, Sempf J, Oberley T, Sioutas C, Yeh JI, Wiesner MR, Nel AE: Comparision of the abilities of ambient and manufactured nanoparticles to induce cellular toxicity according to an oxidative stress paradigm. Nano Lett. 8:1794-1807, 2006.

Zhang Y, Sun J: A Study on the bio-safety for nano-silver as anti-bacterial materials. Chin. J. Med. Instrum. 31:35-38, 2007b.

Zhang Y, Chen F, Zhuang J: Synthesis of silver nanoparticles via electrochemical reduction on compact zeolite film modified electrodes. Chem. Commun. (Camb.) 7:2814-2815, 2002. 